\title{
Assessing the performance of Polish Regional Funds for Environmental Protection and Water Management using DEA model
}

\author{
Joanicjusz Nazarko ${ }^{1 *}$, and Ewa Chodakowska ${ }^{1}$ \\ ${ }^{1}$ B ialystok U niversity of Technology, Faculty of Engineering M anagement, W iejska 45A, \\ 15-351 Bialystok, Poland
}

\begin{abstract}
The public sector is under growing pressure to increase its efficiency. Expectations from the political authorities, local communities, stakeholders and media towards the public-sector entities are high. M odern management methods must be introduced to meet them. Data Envelopment Analysis (DEA) is an important method used in comparative studies of public sector efficiency. Voivodeship Funds for Environmental Protection and Water Management (VFEPWMs) are public entities that financially support actions aimed at environmental protection and water management. Their task is to acquire and redistribute financial resources to support projects related to environmental protection. VFEPWM s face the challenge of increasing the use of available funds and the efficiency of their use. The paper presents the use of DEA method — which is as a modern engineering management tool - to evaluate the VFEPWM $\mathrm{S}$ performance. In the DEA performance analysis of VFEPWM, it is assumed that each unit may be characterised by their input resources, effects, environmental variables and transformation processes that transform resources into effects. V FEPW M s have better performance if they transform resources into desirable effects (actions) more efficiently. The results of the conducted analysis allow comparing the performance of particular VFEPW Ms, to identify model units and to develop benchmarking graphs. The analysis is performed not only to assess the current level of VFEPWM performance but also to acquire information allowing to remove inefficiency.
\end{abstract}

\section{Introduction}

In many countries various public services and public goods like infrastructure [1], education [2] or environmental protection [3] are carried out by specialised government agencies. Public expenditure plays a critical role in ensuring the desired quality level of the natural environment [4-6]. Voivodeship Funds for Environmental Protection and Water Management in Poland (VFEPWMs) have been set up to support the area of public tasks, which is the financial support for environmental protection and water management. They collect but also redistribute funds to projects that aim to protect the environment.

* Corresponding author: j.nazarko@pb.edu.pl 
Apart from 16 VFEPWMs, Poland also has the National Fund for Environmental Protection and Water Management (NFEPWM). Among other things, their mission is effective and efficient support for environmental activities, and the challenge resulting from their strategies: increasing the use of available financial resources as well as the efficiency of the use.

In addition, the dynamics of changes in the operational environment of organisations force the funds to adapt flexibly to changes and challenges related to EU policies and its financial instruments [4]. Therefore, it seems necessary to take an example from other sectors of the economy [7-8] and to assess the performance of the VFEPWMs, to look for benchmarks characterised by relatively higher efficiency in relation to others, and to search for good practices that can be applied.

VFEPWMs and NFEPWM are institutions financing environmental protection. They are not focused on achieving financial profit, but on maximising the ecological effect. In such cases, the use of typical profitability ratios would be inappropriate. This paper responds to the need to demonstrate and test an effective method of the VFEPWMs performance assessment. It also aims at indicating possibilities of the improvement of the effectiveness of public money expenditures on environmental protection.

The analysis was performed using the Data Envelopment Analysis (DEA) method. The DEA has been a recognised and popular method of analysing efficiency in various areas of economy and administration as well as the non-profit sector [9-11]. The world literature on the DEA method has been extensive and is constantly growing. More than 10000 DEA articles have been published until the end of 2017, including both the application and innovative DEA models. Many publications have been published regarding, among others, the assessment of the performance of banks, education institution, and energy sector units. Eco-efficiency is also the subject of many considerations by DEA. Among others, the evaluation was given to countries (12-13) and technologies [14-16]. The analysis of the rich scientific literature suggests that DEA is a robust tool for the efficiency analysis of the public administration units. The legitimacy and the utility of DEA application to such problems is a grounded scientific opinion [17-18].

The article attempts to answer the question about the performance of Polish Regional Funds for Environmental Protection and Water Management. Authors evaluated changes in efficiency during 2011-2015. The presented dynamic analyses give a general idea of the financial resources that are administered in relation to their redistribution in 16 VFEPWMs over time. NFEPWM operates on a much larger scale, carrying out as many tasks as all voivodship funds together. At the same time, there are no other adequate entities for benchmarking. The analysis of the performance of the Polish Regional Funds was developed on the basis of their financial statements.

\section{Methods and data consideration}

Data Envelopment Analysis (DEA), introduced by Charnes et al. (1978) [19], is a powerful method for measuring the relative efficiency of a set of homogeneous decision-making units (DMUs). DEA has proved to be a useful tool for assessing the performance of various organisations and systems. The DEA assumes that each unit may be characterised by their input resources, effects, environmental variables and processes that transform resources into effects. The DEA evaluates systems with multiple inputs and outputs and provides a synthetic indicator that considers the strengths of each analysed unit (Fig. 1). 


\section{factors outside management control \\ (environmental variables)}
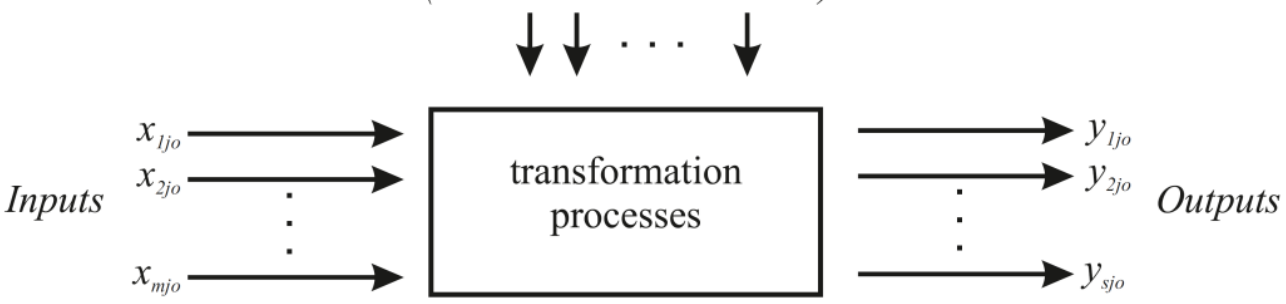

Fig. 1. Concept of DEA input-output assessment.

Mathematically, the idea of DEA for $n$ DMUs, $m$ different inputs and $s$ different outputs: $x_{i j}, y_{r j}$ where $j=1,2, \ldots, j_{\mathrm{O}}, \ldots, n ; i=1,2, \ldots, m ; r=1,2, \ldots s$ can be written in the form of equations (1). The standard variable return to scale input-oriented radial DEA model (BCC-I DEA) for evaluating the efficiency of $\mathrm{DMU}_{j o}$ is [20]:

$\min \theta_{j_{O}}$

$\sum_{j=1}^{n} \lambda_{j} x_{i j} \leq \theta_{j_{O}} x_{i j_{O}}, \forall i$

$\sum_{j=1}^{n} \lambda_{j} y_{r j} \geq y_{r_{0}}, \forall r$

$\sum_{j=1}^{n} \lambda_{j}=1$,

$j=1, \ldots, n$,

where:

$X_{j}=\left(x_{1 j}, x_{2 j}, x_{3 j}, \ldots, x_{m j}\right)$ - input vector,

$Y_{j}=\left(y_{1 j}, y_{2 j}, y_{3 j}, \ldots, y_{s j}\right)$ - output vector,

$\lambda_{j}$ - vector of weights specifying the intensity of the use of reference objects' technologies in optimal $j$-th DMU's technology.

Considering the potential variables for the VFEPWMs' assessment, the operational specificity of the funds should be considered. Revenues and outlays of the funds are determined by legal regulations. Revenues of funds may include money from the state budget, the European Union budget and other foreign sources. In addition, the funds may receive income from issuing their own bonds and take out loans and borrowings. The revenues of all funds can be used only for purposes related to environmental protection. Environmental financing may take the form of interest-bearing loans, subsidies, including subsidies for interest on bank loans, partial repayment of bank loans, interest subsidies or redemption prices for bonds or subsidies for dismantling end-of-life vehicles.

As a basis for building a synthetic efficiency indicator using the DEA method, variables controlled by the funds were selected. Interest income and the sum of loans and subsidy financing were used as outputs (effects), operating costs - as inputs, and revenue from fees and penalties -as an independent variable affecting the functioning of the fund. The inputoriented model was chosen because it was assumed that operating costs should be minimised in the existing financing system. Table 1 presents a summary of the characteristics of the considered variables; Table 2 gives the correlation coefficients between variables.

Table 1. Variable statistics 2011-2015, [PLN]

\begin{tabular}{|l|r|r|r|r|}
\hline & Mean & Min & Max & Std. err. \\
\hline Operating expenses $X_{1}$ & 8644752 & 4125016 & 16673333 & 3647270 \\
\hline Interest income $Y_{1}$, & 15016582 & 2447673 & 41289166 & 10307955 \\
\hline Total financing $Y_{2}$ & 152746257 & 18835909 & 493728292 & 104927149 \\
\hline Revenue from fees and penalties $Z_{1}$ & 38318964 & 5102928 & 132490672 & 30018183 \\
\hline
\end{tabular}


Table 2. Correlation coefficients between variables in 2011-2015

\begin{tabular}{|l|l|l|l|}
\hline & $X_{1}$ & $Y_{1}$ & $Y_{2}$ \\
\hline$Z_{1}$ & 0.791 & 0.830 & 0.804 \\
\hline$X_{1}$ & & 0.772 & 0.817 \\
\hline
\end{tabular}

Next, the analysis of the relationship between variables must be underlined. A high correlation of variables can be noted. Operating costs are highly correlated with the total funding (Pearson's correlation coefficient is over 0.8) and revenue from fees and penalties is highly correlated with interest income and the sum of financing.

Considering the above, the final model was accommodated with the value of the total financing in relation to revenues from fees and penalties, the value of interest income in relation to revenues from fees and penalties as output variables (effects), and, on the side of input (resources), operating costs in relation to revenues from fees and penalties. The strength of the linear relationship between the selected variables is illustrated in Table 3 . The $\mathrm{DMU}_{j o}$ model scheme is shown in Fig. 2.

Table 3. Correlation coefficients between variables 2011-2015

\begin{tabular}{|l|c|c|}
\hline & $Y_{1} / Z_{1}$ & $Y_{2} / Z_{1}$ \\
\hline$X_{1} / Z_{1}$ & 0.409 & 0.582 \\
\hline$Y_{1} / Z_{1}$ & & 0.680 \\
\hline
\end{tabular}

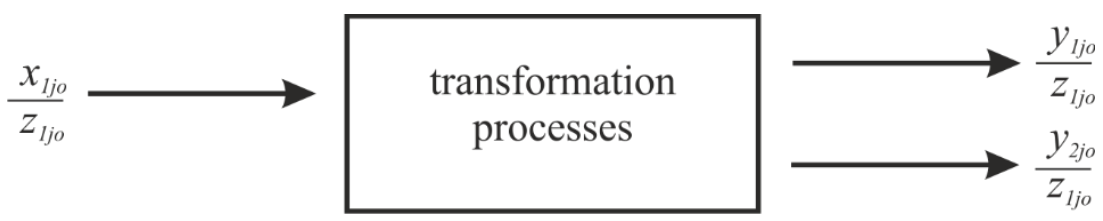

Fig. 2. DEA model for assessing the performance of Polish Regional Funds for Environmental Protection and Water Management

Since data includes ratio variables, the non-linear corrected model suggested in [21] in the presence of input-ratios and/or output-ratios with modified convexity assumption was adopted. Altered input-oriented DEA BCC model with input-ratio and output-ratio for VFEPWMs' is:

$$
\begin{aligned}
& \min \theta_{j_{O}} \\
& \sum_{j=1}^{n} \lambda_{j} x_{1 j}-\theta_{j_{O}} \frac{x_{1 j_{O}}}{z_{1 j_{O}}} \sum_{j=1}^{n} \lambda_{j} z_{1 j} \leq 0, \\
& \sum_{j=1}^{n} \lambda_{j} y_{r j}-\frac{y_{r j_{O}}}{z_{1 j_{O}}} \sum_{j=1}^{n} \lambda_{j} z_{1 j} \geq 0, \forall r \\
& \sum_{j=1}^{n} \lambda_{j}=1, \\
& j=1 . \ldots . n .
\end{aligned}
$$

It can be pointed out that due to the data assumptions there are no significant differences in the final results between the model (1) and (2) but only in the technologies benchmarks. The changes in productivity over time were measured using the productivity index developed by Malmquist (1953) [22] as a quantitative index of the use of inputs and first combined with the DEA [23]. Its construction is based on a comparison of the relation of inputs and outputs in time periods $t$ and $t+1$. Productivity changes over time in Malmquist Index (MI) can be decomposed into changes in efficiency and technology. The relative overall technical efficiency change (catch-up) for DMUjo is defined as:

$$
T E C=\frac{D^{t+1}\left(x^{t+1}, y^{t+1}\right)}{D^{t}\left(x^{t}, y^{t}\right)}
$$

The frontier change between $t$ and $t+1$ is calculated as follows: 
$T C=\left[\frac{D^{t}\left(x^{t}, y^{t}\right)}{D^{t+1}\left(x^{t}, y^{t}\right)} \times \frac{D^{t}\left(x^{t+1}, y^{t+1}\right)}{D^{t+1}\left(x^{t+1}, y^{t+1}\right)}\right]^{1 / 2}$

The overall MI is calculated by multiplying the overall efficiency change and technology change at periods $t$ and $t+1$ :

$M I^{t+1}=T E C \times T C=\left[\frac{D^{t}\left(x^{t+1}, y^{t+1}\right)}{D^{t}\left(x^{t}, y^{t}\right)} \times \frac{D^{t+1}\left(x^{t+1}, y^{t+1}\right)}{D^{t+1}\left(x^{t}, y^{t}\right)}\right]^{1 / 2}$

where:

$D^{t}\left(x^{t}, y^{t}\right) \quad$ - the efficiency of a unit transforming input $x$ into outputs $y$ in period $t$,

$D^{t+1}\left(x^{t+1}, y^{t+1}\right)$ - the efficiency of a unit transforming input $x$ into outputs $y$ in period $t+1$,

$D^{t+1}\left(x^{t}, y^{t}\right) \quad$ - the efficiency of a unit in period $t$ in relation to the frontier in period $t+1$,

$D^{t}\left(x^{t+1}, y^{t+1}\right)$ - the efficiency of a unit in period $t+1$ in relation to the frontier in period $t$.

The interpretation of $\mathrm{MI}$ is as follows: $\mathrm{MI}>1$ means an increase in productivity, progress; MI $<1$ decrease in productivity, regress; and MPI $=1$ no change in productivity at time $t+1$ in comparison with $t$.

Assessing the performance of VFEPWMs' completes with the benchmarks indication.

\section{Results and discussions}

The assessment of Polish regional funds for environmental protection and water management using DEA model is presented in Table 4 and illustrated in Fig. 3. Calculations were carried out with the use of a Microsoft Excel spreadsheet designed by the authors.

Table 4. Efficiency of VFEPWMs in 2011-2015 DEA BCC-I

\begin{tabular}{|c|r|r|r|r|r|}
\hline $\begin{array}{l}\text { Voivodeship } \\
\text { Code }\end{array}$ & 2011 & 2012 & 2013 & 2014 & 2015 \\
\hline V1 & $56.90 \%$ & $68.30 \%$ & $100.00 \%$ & $100.00 \%$ & $100.00 \%$ \\
\hline V2 & $59.70 \%$ & $74.10 \%$ & $79.50 \%$ & $91.20 \%$ & $74.10 \%$ \\
\hline V3 & $50.40 \%$ & $59.60 \%$ & $57.40 \%$ & $90.20 \%$ & $64.00 \%$ \\
\hline V4 & $33.60 \%$ & $36.20 \%$ & $49.90 \%$ & $40.20 \%$ & $44.40 \%$ \\
\hline V5 & $79.10 \%$ & $88.20 \%$ & $79.70 \%$ & $78.80 \%$ & $97.50 \%$ \\
\hline V6 & $100.00 \%$ & $100.00 \%$ & $100.00 \%$ & $100.00 \%$ & $100.00 \%$ \\
\hline V7 & $68.10 \%$ & $60.10 \%$ & $61.80 \%$ & $60.40 \%$ & $74.50 \%$ \\
\hline V8 & $100.00 \%$ & $100.00 \%$ & $74.80 \%$ & $100.00 \%$ & $64.60 \%$ \\
\hline V9 & $39.00 \%$ & $43.10 \%$ & $47.10 \%$ & $44.80 \%$ & $45.50 \%$ \\
\hline V10 & $100.00 \%$ & $29.70 \%$ & $29.70 \%$ & $26.70 \%$ & $30.70 \%$ \\
\hline V11 & $61.60 \%$ & $64.70 \%$ & $81.80 \%$ & $58.30 \%$ & $82.70 \%$ \\
\hline V12 & $100.00 \%$ & $100.00 \%$ & $100.00 \%$ & $100.00 \%$ & $100.00 \%$ \\
\hline V13 & $57.50 \%$ & $61.20 \%$ & $65.30 \%$ & $63.40 \%$ & $66.00 \%$ \\
\hline V14 & $41.50 \%$ & $22.80 \%$ & $37.40 \%$ & $25.30 \%$ & $38.60 \%$ \\
\hline V15 & $52.50 \%$ & $56.10 \%$ & $62.70 \%$ & $56.50 \%$ & $69.80 \%$ \\
\hline V16 & $48.60 \%$ & $50.80 \%$ & $46.30 \%$ & $55.90 \%$ & $46.00 \%$ \\
\hline
\end{tabular}




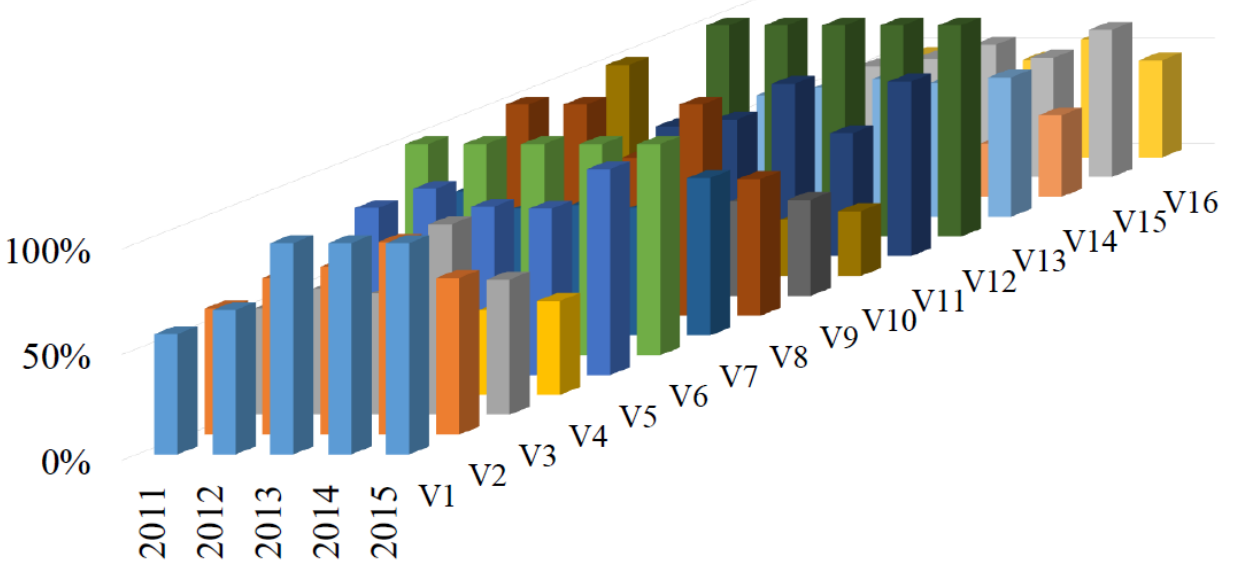

Fig. 3. Efficiency of 16 VFEPWMs' during 2011-2015

Evaluation of funds using the BCC-I DEA model considering operational costs, interest income and the sum of financing has emerged leaders, which in 2015 are funds in the voivodships V1, V6 and V12. Too high operating costs in relation to revenue and the total funding are observed in funds in V10 and V14 but also in V4, V9 and V16.

Perhaps, it would be worth reconsidering the idea of different financing of inefficient funds, which have been characterised by the lowest revenues from fees and penalties. An important argument in favour of "equalling" the level of voivodeship fund revenues is the higher quality of the natural environment, a higher percentage of naturally valuable areas in the area of "poor" funds. Supporting municipal investments as well as co-financing projects in the field of biodiversity and landscape protection, resulting from the need to maintain high environmental standards, exceeds the limited resources available to these funds. Meanwhile, the return of funds to individual provincial funds is directly proportional to payments made of environmental fees and penalties, whose amount depends on the region's economic development.

Malmquist index indicates that the leader in terms of change in the efficiency is V1. In the analysed period, funds decreased only in V16 and V13. The number of funds that recorded an increase in efficiency is ten out of sixteen regional funds in 2015 and eight in 2014. Particularly positive is the fact that the increase was noted in the funds with the lowest efficiency, i.e. in V4, V10 and V14. 
Table 4. Malmquist Index, technical efficiency change and the frontier change of VFEPWMs in 2011-2015

\begin{tabular}{|l|c|c|c|c|c|c|c|c|c|c|c|c|}
\hline & \multicolumn{9}{|c|}{ MI } & \multicolumn{5}{|c|}{ TEC } & \multicolumn{3}{|c|}{ TC } \\
\hline $\begin{array}{l}\text { Voivodeship } \\
\text { Code }\end{array}$ & 2012 & 2013 & 2014 & 2015 & 2012 & 2013 & 2014 & 2015 & 2012 & 2013 & 2014 & 2015 \\
\hline V1 & 1.060 & 1.055 & 0.999 & 1.144 & 1.200 & 1.465 & 1.000 & 1.000 & 0.883 & 0.720 & 0.999 & 1.144 \\
\hline V2 & 1.009 & 0.894 & 1.136 & 0.794 & 1.242 & 1.072 & 1.147 & 0.813 & 0.813 & 0.834 & 0.991 & 0.977 \\
\hline V3 & 1.027 & 0.907 & 1.636 & 0.674 & 1.183 & 0.962 & 1.572 & 0.710 & 0.867 & 0.942 & 1.041 & 0.950 \\
\hline V4 & 0.980 & 1.391 & 0.688 & 1.111 & 1.077 & 1.377 & 0.806 & 1.104 & 0.909 & 1.011 & 0.853 & 1.006 \\
\hline V5 & 1.025 & 0.704 & 1.189 & 1.063 & 1.115 & 0.905 & 0.988 & 1.238 & 0.920 & 0.778 & 1.204 & 0.859 \\
\hline V6 & 0.929 & 0.779 & 1.041 & 1.049 & 1.000 & 1.000 & 1.000 & 1.000 & 0.929 & 0.779 & 1.041 & 1.049 \\
\hline V7 & 0.808 & 0.887 & 1.240 & 1.087 & 0.883 & 1.027 & 0.977 & 1.234 & 0.915 & 0.863 & 1.268 & 0.881 \\
\hline V8 & 1.096 & 0.814 & 1.053 & 0.673 & 1.000 & 0.748 & 1.337 & 0.646 & 1.096 & 1.088 & 0.788 & 1.043 \\
\hline V9 & 0.963 & 1.141 & 0.736 & 1.010 & 1.104 & 1.093 & 0.953 & 1.014 & 0.873 & 1.044 & 0.773 & 0.996 \\
\hline V10 & 0.289 & 1.439 & 0.654 & 1.023 & 0.297 & 1.002 & 0.900 & 1.146 & 0.973 & 1.436 & 0.726 & 0.892 \\
\hline V11 & 0.938 & 0.943 & 0.882 & 1.357 & 1.051 & 1.263 & 0.712 & 1.420 & 0.893 & 0.746 & 1.238 & 0.956 \\
\hline V12 & 0.795 & 0.675 & 1.294 & 0.874 & 1.000 & 1.000 & 1.000 & 1.000 & 0.795 & 0.675 & 1.294 & 0.874 \\
\hline V13 & 0.977 & 0.918 & 0.914 & 0.889 & 1.064 & 1.068 & 0.970 & 1.041 & 0.918 & 0.860 & 0.942 & 0.853 \\
\hline V14 & 0.547 & 1.873 & 0.532 & 1.465 & 0.550 & 1.639 & 0.676 & 1.527 & 0.994 & 1.143 & 0.786 & 0.959 \\
\hline V15 & 0.937 & 0.954 & 1.151 & 1.083 & 1.069 & 1.118 & 0.901 & 1.235 & 0.877 & 0.854 & 1.277 & 0.877 \\
\hline V16 & 0.941 & 0.973 & 0.876 & 0.690 & 1.044 & 0.913 & 1.207 & 0.822 & 0.901 & 1.066 & 0.726 & 0.839 \\
\hline
\end{tabular}

Another advantage of DEA method is the possibility of using its results in the benchmarking analysis. Benchmarking analysis allows to identify best practices in the fully efficient units and to point at measures which would lead to the performance improvement in the inefficient units. Benchmarking graph created on the basis of data from Table 6 is presented in Fig. 4.

Table 6. Benchmarks for inefficient funds in 2015

\begin{tabular}{|l|l|l|l|l|l|l|}
\hline $\begin{array}{l}\text { Voivodeship } \\
\text { Code }\end{array}$ & \multicolumn{3}{|c|}{$\lambda_{j}$} & \multicolumn{3}{c|}{ Benchmarks (code) } \\
\hline V1 & 1 & & & 1 & & \\
\hline V2 & 0.428 & 0.572 & & 1 & 12 & \\
\hline V3 & 0.453 & 0.547 & & 6 & 12 & \\
\hline V4 & 0.743 & 0.257 & & 1 & 12 & \\
\hline V5 & 0.173 & 0.827 & & 1 & 12 & \\
\hline V6 & 1 & & & 6 & & \\
\hline V7 & 0.113 & 0.887 & & 1 & 12 & \\
\hline V8 & 0.142 & 0.804 & 0.054 & 1 & 6 & 12 \\
\hline V9 & 0.335 & 0.379 & 0.286 & 1 & 6 & 12 \\
\hline V10 & 0.349 & 0.651 & & 1 & 6 & \\
\hline V11 & 0.623 & 0.377 & & 1 & 12 & \\
\hline V12 & 1 & & & 12 & & \\
\hline V13 & 0.601 & 0.399 & & 6 & 12 & \\
\hline V14 & 0.820 & 0.180 & & 1 & 12 & \\
\hline V15 & 0.171 & 0.829 & & 1 & 12 & \\
\hline V16 & 0.900 & 0.100 & & 6 & 12 & \\
\hline
\end{tabular}




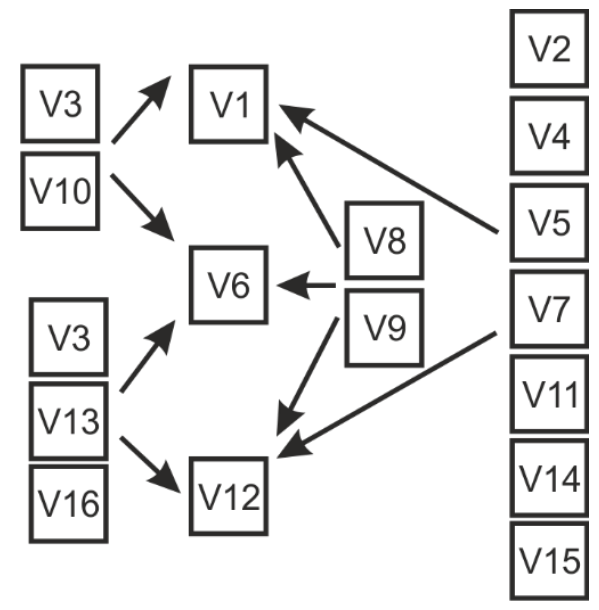

Fig. 4. Benchmark graph of 16 VFEPWMs in 2015

On the basis of the benchmarking graph fully efficient units may be identified. Their technology is a model for inefficient funds. Funds V1 and V12 draw special attention as they are, together, benchmarks for most of the other inefficient VFEPWMs.

\section{Conclusions}

Efficiency benchmarking plays a key role in policy analysis worldwide, given the limited resources available. Efficiency improvement is often regarded as one of the most important goals of many social and economic policies and reforms. The article presents the assessment of the performance of Polish regional funds for environmental protection and water management. The scale of financing operations of the funds can be described by the total funding allocated for the environment protection projects. In the analysed period of 2011-2015, VFEPWMs' redistributed PLN 23511603204 to projects related to environmental protection. Their operating costs amounted to PLN 1254044150.

The DEA performance analysis of VFEPWM allowed to compare the performance of particular funds and to indicate the ones that perform better and transform resources into desirable effects more efficiently. The noted differences could serve as an argument for government policy changes on the functioning of the funds and financing, but above all should become an inspiration to limit the operating costs of VFEPWMs.

Obtained results point at considerable possibilities of increasing the efficiency of public funds utilisation by the majority of VFEPWMs. Benchmarking graph developed on the basis of DEA analysis reveals that units V1, V6 and V12 may be treated as reference units and that their practices should be a basis for improving the performance of the remaining funds.

The analysis of VFEPWMs performance presented in this paper was solely based on the financial results of particular units. Environmental effects such as reduction of greenhouse gases emission, an increase of energy consumption from renewable energy sources or improved quality of water and air were not taken into consideration. Further research on VFEPWMs effectiveness should also include that dimension. 


\section{References}

1. J. Nazarko, P. Radziszewski, K. Dębkowska, J. Ejdys, A. Gudanowska, K. Halicka, J. Kilon, A. Kononiuk, K. Kowalski, J. Król, L. Nazarko, M. Sarnowski, T. Vilutiene, Foresight Study of Road Pavement Technologies, Procedia Engineering, 122, 129-136 (2015)

2. F. van V ught, U. B randenburg, N. Burquel, D. Carr, G. Federkeil, J. A. dos Santos Rafael, J. Sadlak, J. U rban, P. W ells, D. W esterheijden, J. Nazarko, K. K uzmicz, A practical guide. Benchmarking in European Higher Education, ESM U, B russels (2008)

3. The Directory of Environmental Organizations and Environmental Government A gencies in Europe. U nited States Environmental Directories, [online] https://earthdirectory.net/europe\#A gencies [11.07.2018]

4. F. Cucchiella, I. D'Adamo, M. Gastaldi, S. C. L. Koh, P. Rosa, A comparison of environmental and energetic performance of European countries: A sustainability index, Renewable and Sustainable Energy Reviews, 78, 401-413 (2017)

5. G. E. Halkos, P. A. Paizanos, The effect of government expenditure on the environment: A n empirical investigation, Ecological Economics, 91, 48-56 (2013)

6. R. López, G. I. Galinato, A . Islam, Fiscal spending and the environment: Theory and empirics, J ournal of Environmental Economics and M anagement, 62(2), 180-198 (2011)

7. J. Nazarko, Regionalny foresight gospodarczy. Scenariusze rozwoju innowacyjności mazowieckich przedsi ębiorstw, ZPWiM, Warszawa (2013)

8. K. Dziekoński, O. H. M. F. Ibrahim, A-M . M ahamadu, P. M anu, Framew ork of performance measurement practices in construction companies in Egypt, Engineering $M$ anagement in Production and Services, 10(2), 7-14 (2018)

9. E. Chodakowska, J. Nazarko, N etwork DEA M odels for Evaluating Couriers and M essengers, Procedia Engineering, 182, 106-111 (2017)

10. A. Emrouznejad, G. Y ang, A survey and analysis of the first 40 years of scholarly literature in DEA : 1978-2016, Socio-Economic Planning Sciences, 61, 4-8 (2018)

11. K. Halicka, M ain Concepts of Technology A nalysis in the Light of the L iterature on the Subject, Procedia Engineering, 182, 291-298 (2017)

12. E. Chodakowska, J. Nazarko, Environmental DEA method for assessing productivity of European countries, Technological and Economic Development of Economy, 23(4), 589-607 (2017)

13. J. Nazarko, E. Chodakowska, L abour efficiency in construction industry in Europe based on frontier methods: data envelopment analysis and stochastic frontier analysis, Journal of Civil Engineering and M anagement, 23(6), 787-795 (2017)

14. A. Shabani, R. F. Saen, S. M. R. Torabipour, A new data envelopment analysis (DEA) model to select eco-efficient technologies in the presence of undesirable outputs, Clean Technologies and Environmental Policy, 16(3), 513-525 (2014)

15. D. S. K won, J. H. Cho, S. Y. Sohn, Comparison of technology efficiency for $\mathrm{CO} 2$ emissions reduction among European countries based on DEA with decomposed factors, Journal of Cleaner Production, 151, 109-120 (2017)

16. K. Halicka, The reference methodology of prospective analysis of technology in production engineering. In: S. Şahin (ed.) 8th International Conference on 
Engineering, Project, and Product Management (EPPM 2017). Proceedings Lecture Notes in Mechanical Engineering, Springer, Cham, 99-107 Springer (2018)

17. H. A hn, M. A fsharian, A. Emrouznejad, R. B anker, Recent developments on the use of DEA in the public sector, Socio-Economic Planning Sciences, 61, 1-3 (2018)

18. A. M ardani, D. Streimikiene, T. Balezentis, M. Z. M. Saman, K. M. Nor, S. M. K hoshnava, Data Envelopment A nalysis in Energy and Environmental Economics: A $n$ Overview of the State-of-the-A rt and Recent Development Trends, Energies, 11(8) (2018)

19. A. Charnes, W.W. Cooper, E. Rhodes, M easuring the efficiency of decision-making units, European J ournal of O perational Research, 2(6), 429-444 (1978)

20. W. W. Cooper, L. M. Seiford, K. Tone, Data Envelopment Analysis. A Comprehensive Text with Models. Applications. References and DEA-Solver Software. Second Edition, Springer (2007)

21. A. Emrouznejad, G. R. A min, DEA models for ratio data: Convexity consideration, A pplied M athematical M odelling 33(1), 486-498 (2009)

22. S. Malmquist, Index Numbers and Indifference Surfaces, Trabajos de Estadística, 4(2), 209-242 (1953)

23. R. Färe, S. Grosskopf, B. Lindgren, P. Roos, Productivity Changes in Swedish Pharamacies 1980-1989: A Non-Parametric M almquist A pproach, J ournal of Productivity A nalysis, 3(1/2), 85-101 (1992) 